\title{
Fanatisme Penggemar K-Pop Melalui Media Sosial (Studi pada Akun Instagram Fanbase Boyband iKON)
}

\author{
Wishandy, Riris Loisa, Lusia Savitri Setyo Utami \\ wishandy97@yahoo.com, ririsl@fikom.untar.ac.id,lusias@fikom.untar.ac.id
}

Fakultas Ilmu Komunikasi Universitas Tarumanagara

\begin{abstract}
K-Pop as popular culture has spread throughout the world, especially in Indonesia. K-Pop is a music industry that consists of girlband and boyband, one of them is boyband iKON. As time goes on, fans can easily access any information about iKON using new media, for example, Instagram. By using Instagram, iKON fans can vent their love and admiration for $i K O N$ by watching videos, news, and handsome photos of $i K O N$. This triggered fans to become increasingly in love and admiration for $i K O N$ which later caused fanaticism. This study aims to determine the extent of fanaticism behavior of fans in social media regarding their love for $i K O N$. This research is qualitative research. The method used in this study is a case study. The data analyzed is obtained from the results of interviews with the admin of iKON fanbase account on Instagram, namely @ikonictreazure and @Wowfaktaikon. The result of this study is that fans feel love and admiration by showing fanatical behaviors seen from fans' responses when commenting on Instagram.
\end{abstract}

Keyword: Pop culture, New media, Fanaticism, Fandom

\begin{abstract}
Abstrak
Budaya populer K-Pop telah mewabah sampai keseluruh dunia terutama di Indonesia. K-Pop merupakan industri musik yang terdiri dari girlband dan boyband, salah satunya yaitu boyband iKON. Semakin berkembangnya zaman, penggemar dapat dengan mudah mengakses informasi apapun mengenai iKON menggunakan media baru atau new media, salah satunya yaitu media sosial Instagram. Dengan menggunakan Instagram, penggemar dan fandom iKON dapat melampiaskan rasa cinta dan kagumnya terhadap iKON dengan melihat video, berita dan foto-foto tampan dari anggota iKON. Hal tersebut memicu penggemar semakin cinta dan kagum terhadap iKON yang telah menimbulkan fanatisme terhadap idolanya. Penelitian ini bertujuan untuk mendeskripsikan perilaku fanatisme penggemar dalam media sosial mengenai kecintaannya terhadap boyband iKON. Penelitian ini merupakan penelitian kualitatif. Metode yang digunakan dalam penelitian ini yaitu studi kasus. Data yang dianalisis diperoleh dari hasil wawancara dengan admin akun fanbase iKON di Instagram yaitu@ikonictreazure dan@Wowfaktaikon. Hasil dari penelitian ini adalah bahwa penggemar merasakan cinta dan kagum yang tinggi dengan menunjukan perilaku-perilaku fanatik terlihat dari respon penggemar saat berkomentar dalam Instagram.
\end{abstract}

Kata Kunci: Budaya Populer, New Media, Fanatisme, Fandom 


\section{Pendahuluan}

Indonesia terpilih menjadi tuan rumah dalam menyelenggarakan ajang olahraga bergengsi yaitu Asian Games ke-18. Kesuksesan berjalannya acara juga disambut dengan baik bersama prestasi atlet tanah air. Pada penutupan Asian Games JakartaPalembang 2018 yang bertajuk Closing Ceremony Asian Games Jakarta-Palembang 2018 di Gelora Bung Karno tampak berbeda dengan pembukaan Asian Games Jakarta-Palembang 2018. Penutupan Asian Games Jakarta-Palembang 2018 ini menjadi sorotan dunia karena disebut sebagai Asian Games terbaik dalam sejarah (https://www.liputan6.com/global/read/3635002/jadi-sorotan-dunia-jakarta-

palembang-2018-disebut-sebagai-asian-games-terbaik-dalam-sejarah diakses pada 5 maret 2019 pukul 13.20).

Closing Ceremony Asian Games Jakarta-Palembang 2018 menjadi trending topic dunia pada platform twitter melalui tagar \#ClosingCeremonyAsianGames 2018 (http://jateng.tribunnews.com/2018/09/03/closing-ceremony-asian-games-2018-disugbk-jadi-trending-topic-dunia, diakses pada 5 maret 2019 pukul 12.52). Kesuksesan acara tersebut turut mengundang dua artis papan atas yang berasal dari Korea Selatan yaitu iKON dan SUPER JUNIOR, untuk berpartisipasi dalam mengisi acara tersebut. Penampilan mereka di atas panggung sukses menarik perhatian masyarakat Indonesia berkat lagu-lagunya.

Grup boyband yang bernama iKON dibentuk oleh salah satu agensi musik besar di Korea Selatan yaitu YG Entertainment. Grup boyband iKON sendiri dibentuk oleh pemimpin sekaligus pemilik dari YG Entertainment yang bernama Yang Hyun Suk. Boyband iKON sendiri beranggotakan tujuh orang personil yang bernama B.I, Bobby, JAY, DK, SONG, JU-NE dan CHAN. Agensi iKON akhirnya memberikan nama fandom resmi untuk para fans iKON dengan sebutan iKONIC.

Grup boyband iKON pun semakin naik daun dan menarik hati penggemar dari berbagai kalangan khususnya di Indonesia, berkat lagunya yang berada di peringkat pertama dan bertahan di puncak chart music Billboard Korea yang berjudul "Love Scenario". Penggemar atau fans dari grup tersebut diketahui semakin bertambah jumlahnya di Indonesia dikarenakan iKON telah mengisi acara pada Closing Ceremony Asian Games 2018 dan berhasil memberikan performa yang luar biasa dengan membawakan lagu "Love Scenario" dan "Rhythm Ta" yang diadakan di Gelora Bung Karno (https://kumparan.com/@kumparank-pop/ikon-bawakan-duabuah-lagu-di-penutupan-asian-games-2018-1535895768969013285, diakses pada tanggal 5 maret 2019 pukul 13.53).

Penggemar atau fans pada dasarnya sekumpulan orang yang memiliki rasa kagum terhadap seseorang atau grup tertentu. Ada pihak tertentu yang dapat menyatukan penggemar agar dapat mendapatkan informasi yang up to date di dalam suatu media sosial yaitu akun fanbase. Akun Fanbase adalah forum media sosial yang mengelola informasi terkini terkait aktivitas idola untuk dikonsumsi oleh penggemar. Peran akun fanbase sangat dibutuhkan dalam mengunggah aktivitas idola ke dalam media sosial contohnya seperti mengunggah fancam idola saat konser dan aktivitas fansign idola. Fancam adalah rekaman berupa video yang diambil oleh fans ketika idola sedang tampil dalam sebuah acara sedangkan fansign merupakan sebuah kegiatan yang dilakukan agar fans dan idola bisa bertemu dan bertatap muka lebih dekat dengan cara berjabat tangan, tanda tangan album dan lain lain. Dalam membentuk sebuah akun fanbase, diperlukan orang orang yang memiliki rasa cinta dan fanatisme yang tinggi terhadap idola yang mereka sukai agar akun fanbase tetap 
berjalan dengan lancar dan konsisten dalam memposting video apapun yang berkaitan dengan idolanya tersebut. Menurut Seregina dkk (2011:12), fanatisme merupakan fenomena sangat penting dalam budaya modern dan realitas pribadi dan di sosial masyarakat, hal ini karena budaya sekarang sangat berpengaruh besar terhadap individu dan hubungan yang terjadi di diri individu menciptakan suatu keyakinan dan pemahaman berupa hubungan, kesetiaan, pengabdian dan sebagainya. Perlu diketahui, dalam membentuk akun Fanbase merupakan murni keinginan pribadi tanpa bayaran apapun dikarenakan akun-akun yang dibuat adalah akun yang tidak resmi maka Instagram tidak akan memberikan bayaran apapun terhadap postingan yang tidak resmi.

Akun fanbase hanya memiliki satu tujuan yaitu agar idola kesukaannya dapat dikenal oleh masyarakat luas baik dalam negeri maupun luar negeri. Dengan adanya Akun fanbase maka khalayak dapat dengan mudah mengetahui informasi terbaru tentang idola-idola yang disukai contohnya seperti music video teaser yang dirilis oleh akun resmi idola, album-album atau single baru yang akan dirilis oleh idola masing-masing dan juga informasi mengenai jadwal konser yang akan diadakan oleh pihak agensi.

Akun fanbase biasanya memiliki rasa fanatisme dan semangat yang tinggi dalam mendukung idolanya dengan cara apapun agar meningkatkan popularitas dari boyband iKON itu sendiri dan menjadikan boyband iKON menjadi semakin sukses diberbagai negara tidak hanya di Korea Selatan saja. Penggemar biasanya sangat senang jika melihat foto foto dari idolanya. Maka dari itu dengan adanya akun fanbase itu sangatlah penting agar iKON semakin populer di mata masyarakat Indonesia dan bagi khalayak yang belum mengenal iKON dan karya-karyanya, diharapkan dengan adanya akun fanbase ini bisa mengenal iKON lebih dalam. Oleh sebab itu peneliti membuat skripsi dengan mengangkat judul, "Fanatisme Penggemar K-POP Melalui Media Sosial (Studi Pada Akun Instagram Fanbase Boyband iKON)"

\section{Metode Penelitian}

Penelitian ini menggunakan pendekatan penelitian kualitatif. Menurut Moleong (2011: 6), penelitian kualitatif merupakan penelitian yang dipakai untuk menganalisis suatu fenomena apa yang sedang terjadi di dalam masyarakat oleh subjek penelitian dengan cara deskripsi dalam bentuk bahasa dan kata-kata yang menggunakan beraneka macam metode ilmiah.

Peneliti menggunakan pendekatan kualitatif karena peneliti ingin mendapatkan hasil yang lebih akurat dan lebih tepat dengan mewawancarai narasumber langsung agar peneliti lebih mudah mendapatkan informasi yang spesifik dari narasumber tersebut. Dengan menggunakan pendekatan kualitatif dalam penelitian ini, peneliti dapat mengetahui lebih jelas dan lebih dalam tentang bagaimana fanatisme penggemar K-Pop boyband iKON melalui media sosial.

Pada penelitian ini, peneliti menggunakan jenis penelitian kualitatif deskriptif dengan strategi penelitian studi kasus. Menurut Suryabrata (2011: 80-81), studi kasus berguna untuk menginformasikan segala informasi maupun latar belakang dalam proses penelitian yang besar dalam mempelajari ilmu sosial.

Dalam penelitian tersebut, peneliti memilih admin Instagram fanbase @ikonictreazure dan @wowfaktaikon yang kerap mengunggah setiap foto dan video idolanya setiap hari untuk menjadi subjek penelitian. Admin dipilih menjadi subjek 
penelitian karena narasumber sesuai terhadap kriteria yang telah ditentukan. Kriteria subjek penelitian yang peneliti pilih adalah penggemar yang sudah pasti update terhadap informasi seputar iKON dan penggemar yang sudah pasti memiliki rasa cinta yang tinggi terhadap musik boyband idolanya, mengetahui latar belakang dan informasi terkini tentang idola yang digemari. Dalam penelitian ini, peneliti memilih fanatisme penggemar K-pop melalui media sosial untuk menjadi objek penelitian. Peneliti tertarik untuk membahas ini karena peneliti ingin mendeskripsikan perilaku fanatisme penggemar terhadap idolanya.

Metode pengumpulan data yang digunakan peneliti dalam mendapatkan sejumlah informasi yaitu menggunakan observasi, wawancara, dokumen dan data online.

Dalam penelitian ini, peneliti juga menggunakan analisis data untuk menganalisis, Analisis data menurut Moleong (2011: 248) adalah cara yang dilakukan dengan mengorganisasikan data dan memilahnya menjadi satuan yang dapat dengan mudah dikelola dan menemukan pola, menemukan apa yang penting untuk dipelajari, dan memutuskan apa yang dapat diceritakan kepada orang lain. Peneliti menggunakan teknik analisis data kualitatif yang dikemukakan oleh Miles dan Hubermen.

Teknik keabsahan data yang digunakan juga menggunakan triangulasi. Dalam penelitian ini peneliti menggunakan triangulasi metode (Moleong, 2012:330), yaitu dengan melakukan pengumpulan hasil dan pengecekan data penelitian dengan teknik yang bermacam-macam yaitu seperti observasi, dokumentasi, data online dan wawancara untuk mendapatkan hasil yang relevan dan valid.

\section{Hasil Temuan dan Diskusi}

\section{a. Media sosial sebagai penyebar informasi budaya populer}

Menurut Ridwan (2016:63) kebudayaan adalah suatu gaya hidup yang unik dalam suatu komunitas atau kelompok tertentu. Setiap kelompok-kelompok manusia memiliki cara hidup dan bahasa yang unik dan berbeda. Seiring perkembangan jaman, kebudayaan semakin berkembang dalam budaya populer. Menurut Storey (2009:8) budaya populer adalah budaya massa yang dikonsumsi dan diproduksi secara massal yang dimasukkan ke dalam kategori kebudayaan komersil. Budaya pop sendiri pada saat ini menjadi budaya yang digemari oleh masyarakat dan menjadi trend di kalangan masyarakat. Dengan munculnya kebudayaan populer tersebut maka lahirlah musik K-pop salah satunya boyband iKON. Dalam menyebarkan kebudayaan populer yang disebut sebagai K-Pop, komunikasi massa juga berperan penting.

Menurut Nurudin (2011:4), komunikasi massa berasal dari kata mass of media communication (media komunikasi massa). Komunikasi massa merupakan komunikasi yang beraktifitas melalui media massa. Media massa pun kini berperan dalam menyebarkan kebudayaan populer asal Korea Selatan yang disebut sebagai KPop dengan mengandalkan media baru yaitu media sosial. Menurut Lister dkk (2009:77), media baru pun terbentuk dan tercipta karena adanya kemajuan teknologi yang sangat pesat sehingga media baru atau yang di sebut new media sangat diperlukan dalam era modern pada saat ini.

Pada perkembangannya, muncul beberapa aplikasi media sosial yang dapat memudahkan masyarakat dalam mendapatkan informasi salah satunya ialah Instagram. Berkat terciptanya Instagram, banyak sekali terbentuknya akun-akun 
fanbase iKON yang memudahkan penggemar agar dapat bertukar informasi terkait idola dan berinteraksi terhadap sesama penggemar seperti melihat aktifitas idolanya, informasi terbaru terkait idolanya dan jadwal lagu terbaru yang akan dirilis. Instagram pun menjadi media baru yang biasanya digunakan oleh idola sebagai media untuk mempromosikan lagu-lagu dan mendapatkan popularitas.

\section{b. Fanatisme Penggemar melalui Media Sosial}

Pada umumnya penggemar merupakan seseorang yang memiliki rasa cinta dan kagum terhadap sesuatu hal dengan antusias. Dalam dunia K-Pop, penggemar memiliki peran yang besar untuk menentukan popularitas idola. Tanpa adanya dukungan dari penggemar yang setia maka perlahan-lahan ketenaran dari idola pun juga akan pudar bahkan karirnya sebagai idola di industri musik K-Pop bisa terancam bubar jika peminatnya kurang.

iKON termasuk boyband yang memiliki peminat dan penggemar yang sangat banyak terutama di Indonesia. iKON sendiri memiliki fandom yang dinamakan iKONIC. Perlahan-lahan iKON pun sukses menarik hati penggemar dan membuat penggemar jatuh cinta berkat performa yang ditunjukan oleh iKON. iKON sendiri pun semakin populer dan tenar di kalangan penggemar remaja di Indonesia karena lagu yang berjudul "Love Scenario". Semakin populer iKON, semakin meningkat juga rasa kecintaan dan kekaguman penggemar terhadap grup tersebut karena bukan hanya dari musik saja tetapi dari segi ketampanan atau visual yang dimiliki oleh personil iKON. Dengan wajah yang tampan dan memiliki kualitas musik yang baik, maka tidak heran jika banyak sekali penggemar khususnya perempuan yang memiliki rasa cinta dan kagum yang tinggi terhadap iKON. Hal tersebut merupakan penggemar yang memiliki rasa fanatisme.

Menurut Seregina (2011:12) fanatisme merupakan fenomena yang sangat berperan penting dalam budaya populer dan di sosial masyarakat, hal ini karena budaya sekarang sangat berpengaruh besar terhadap individu dan hubungan yang terjadi di dalam diri individu yang telah melahirkan suatu keyakinan dan pemahaman berupa hubungan, kesetiaan, pengabdian, kecintaan, dan sebagainya.

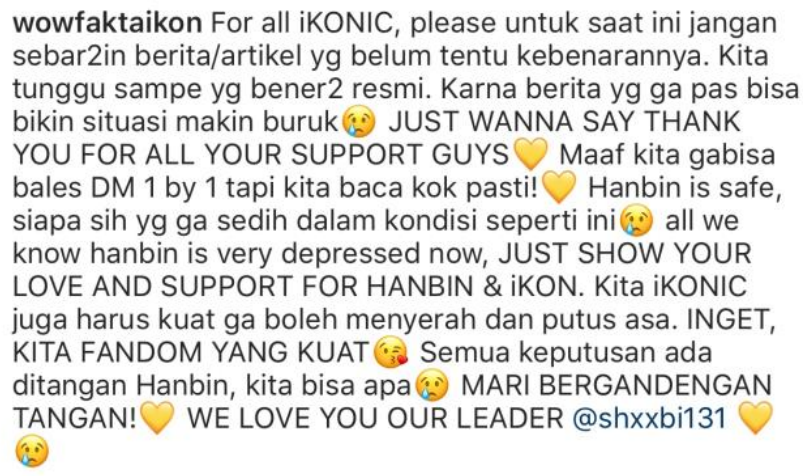

Gambar 1. Komentar oleh@wowfaktaikon 


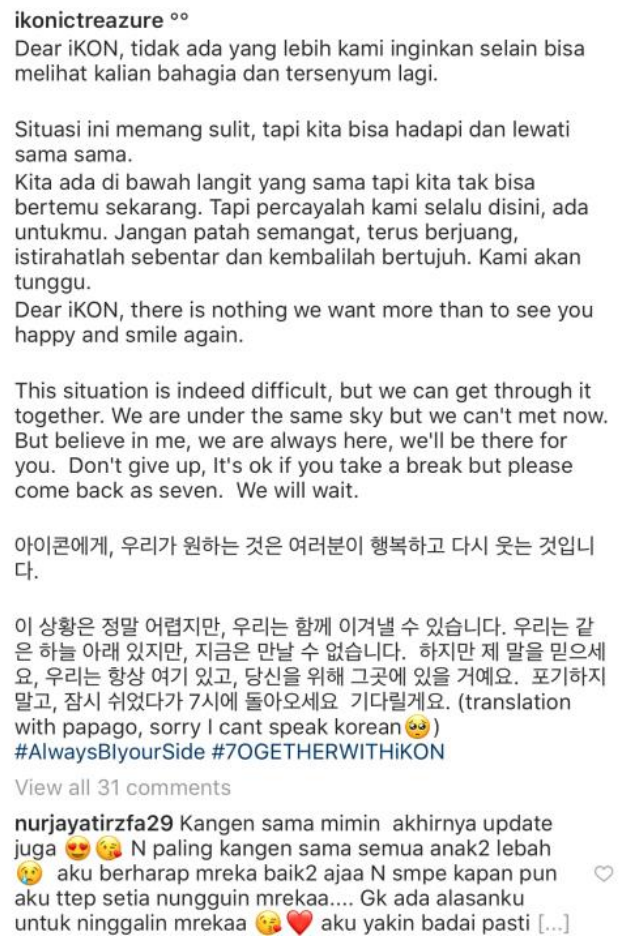

Gambar 2. Caption oleh@ikonictreazure

Komentar dan caption yang diutarakan oleh @ikonictreazure dan @wowfaktaikon merupakan salah satu contoh bentuk fanatisme mereka terhadap iKON melalui Instagram. Selain itu juga dapat terlihat jelas melalui komentarkomentar yang dilontarkan oleh penggemar terkait postingan berita tentang iKON dan respon penggemar yang antusias terhadap iKON. Penggemar memiliki bentuk perilaku fanatisme dengan menunjukkan empati yang terlihat dari penggemar contohnya turut merasa bersedih ketika mendapatkan info tentang leader iKON yaitu B.I yang memutuskan untuk keluar. Empati ini menunjukkan bentuk fanatisme hubungan penggemar dan idola. Kemudian bentuk lainnya adalah kesetiaan dan kecintaan penggemar yaitu dengan memberikan dukungan melalui media sosial pada iKON maupun B.I yang keluar dari grup. Yang terakhir adalah bentuk pengabdian yang terlihat dari penggemar tersebut dengan menunjukkan perilaku adiktif saat mereka tidak bisa hidup tanpa melihat foto, video maupun informasi tentang iKON melalui Instagram.

Media sosial menjadi salah satu alat yang bisa digunakan untuk melihat bagaimana bentuk-bentuk fanatisme fans tersebut. Salah satu media sosial yang menunjukkan bentuk-bentuk kefanatikan fans adalah Instagram. Hal tersebut terutama terlihat melalui postingan-postingan penggemar yang menunjukkan empati mereka terhadap perasaan yang sedang dialami oleh idolanya tersebut. Dari aktivitas penggemar fanatisme yang ada di media sosial, peneliti bisa mengetahui penggemar tersebut merupakan penggemar yang sangat mencintai idolanya. 


\section{Simpulan}

Media sosial berperan dalam menyebarkan berita yang membuat penggemar semakin cinta dan kagum terhadap idola. Penggemar pun menunjukkan rasa cinta dan kagum terhadap idola dengan cara memberikan komentar dan respon ketika mendengar kabar-kabar mengenai idolanya. Mereka beranggapan bahwa bentuk mencintai dan mengagumi idola dapat ditunjukkan dalam berbagai cara termasuk memberikan dukungan di media sosial seperti Instagram. Bentuk dukungan tersebut menjadi salah satu perilaku fanatisme penggemar. Mereka juga beranggapan bahwa perilaku fanatisme merupakan hal yang seharusnya dan wajar dilakukan oleh setiap penggemar kepada idolanya.

\section{Ucapan Terima Kasih}

Ucapan terima kasih yang penulis berikan kepada para narasumber untuk meluangkan waktunya dan memberi informasi kepada penulis selama proses pengumpulan data untuk penelitian ini. Penulis juga mengucapkan terima kasih yang sebesar-besarnya kepada Dosen Pembimbing dan teman-teman serta Fakultas Ilmu Komunikasi Universitas Tarumanagara.

\section{Daftar Pustaka}

Hasan, Rizki Akbar. (2018). Jadi Sorotan Dunia, Jakarta-Palembang 2018 Disebut Sebagai Asian Games Terbaik Dalam Sejarah. Liputan 6. $<$ https://www.liputan6.com/global/read/3635002/jadi-sorotan-duniajakarta-palembang-2018-disebut-sebagai-asian-games-terbaik-dalamsejarah>

Huda, M Nur. (2018). Closing Ceremony Asian Games 2018 Di SUGBK Jadi Trending Topic Dunia. Tribun Jateng. $<$ http://jateng.tribunnews.com/2018/09/03/closing-ceremony-asian-games2018-di-sugbk-jadi-trending-topic-dunia>

Lister, M., et al. (2009). New Media: A Critical Introduction Second Edition. New York: Routledge

Moleong, Lexy J. (2011). Metodologi Penelitian Kualitatif Edisi Revisi. Bandung: PT Remaja Rosdakarya

Moleong, Lexy J. (2012). Metodologi Penelitian Kualitatif. Bandung: Remaja Rosdakarya

Nurudin. (2011). Pengantar Komunikasi Massa. Jakarta:Raja Grafindo Persada

Ridwan, Aang. (2016). Komunikasi Antarbudaya. Bandung: CV Pustaka Setia

Seregina, A., Koivisto, E., dan Mattila, P. (2011). "Fanaticism-Its Development and Meanings in Consumers Lives". Journal of Aalto University School of Economics. 1 (1). 1-106

Storey, John. (2009). Cultural Theory And Popular Culture An Introduction, Fifth Edition. London: Pearson Longman

Suryabrata, Sumadi. (2011). Psikologi Pendidikan. Jakarta: PT. Raja Grafindo Persada 
Vol. 3, No. 1, Juli 2019, 133-140

Wahyudin. (2018). Ikon Bawakan Dua Buah Lagu di Penutupan Asian Games 2018. Kumparan. <https://kumparan.com/@kumparank-pop/ikonbawakan-dua-buah-lagu-di-penutupan-asian-games-2018-

$1535895768969013285>$ 